\title{
Innovations in teacher training based on partnership with employers from the field of additional education
}

\author{
Valentina Abraukhova ${ }^{1, *}$, Maria Schadneva ${ }^{1}$, and Anastasiya Zimovetc $^{1}$ \\ ${ }^{1}$ Don State Technical University, 344003, Gagarin sq., 1, Rostov on Don, Russia
}

\begin{abstract}
This article is devoted to the study of innovations in the training of teachers in modern world and domestic experience on the basis of partnership with employers. The article considers the concept of "partnership" in the field of additional education. Particular emphasis is placed on the characterization of the modern situation, which changes the traditional models of higher education. Models of partnership with employers are considered, using the example of institutions of additional education. Foreign and domestic experience of organizing partnerships with employers for training and professional development of pedagogical personnel is analyzed in detail.
\end{abstract}

\section{Introduction}

The accessibility of knowledge and information to a wide range of consumers creates new challenges for the implementation of pedagogical education and the training of a competent teacher. The transitive state of modern society makes significant changes in all social subsystems. The era of globalization and mobility is changing the relatively stable national career models created in society. In the age of information exchange, borrowing processes are accelerating, foundations and traditions are being violated, paradigms are changing quickly, and the legitimacy of requirements is changing. The beginning of this process was represented in a comparative study in France, Germany, Great Britain and Switzerland, which shows the close relationship of the career model with national institutional contexts, the phenomenon of globalization questions the future of these models and makes significant adjustments [1,2].

Against the backdrop of changes at the macro level, including globalization and technological advances, the need to prepare graduates who are ready for graduation and aware of global education has gained new momentum in the higher education sector. Innovations covered education models, the development of educational programs, the expansion of production and technological practices, the design of educational results and the assessment of the competitiveness of graduates. This is dictated by new standards of higher education, which suggests the need to do even more to ensure that graduates have the necessary skills and qualities to succeed in a globally competitive employment market [3-5].

\footnotetext{
${ }^{*}$ Corresponding author: childrenpalace@mail.ru
} 
The digital revolution of the last two decades has made significant changes in various spheres of human activity, from professional, academic to social. Information and communication technologies (ICTs) facilitated communication and enabled the introduction of new forms of work and learning, overcoming traditional time and space constraints. Lifelong learning has become widespread. Currently, the boundaries of work, study and social activity of mental workers are blurred in one digital environment; this process expands the formation of professional communities that make a significant contribution to changing social processes. The realities of life in the pandemic expanded distance learning opportunities, when almost all educational institutions switched to online education. Since 2015, universities in the United States and Germany have used online blogs as a tutorial. Quantitative analysis assessed the level of participation of students and the content of their publications. Qualitative analysis studied the use of the blog as a tutorial. The results showed that students communicated more on the blog than was required of the teacher. Students rated blogging as a new learning experience [6-8]. Online training is offered by many universities known throughout the world. The London School of Business and Finance, Stanford University, French Polytechnic University École Polytechnique have long used this form of training. In Belarus, BNTU practices distance learning, in Russia Moscow International University, Moscow International Academy and others.

Distance learning makes it possible to make education individual, based on specific needs, and their selection allows you to accurately compare the educational material, the requirements of the teacher and the form of control over the knowledge of students. The undeniable advantage of distance learning is its cost. Distance learning is usually cheaper than traditional university education.

Special tools make online learning interactive and efficient. A common form of training is a webinar. In chat and when using a webcam, students can communicate with each other and the lecturer in real time. E-learning courses require self-control and responsibility from the student, because the student himself decides when and how long he will study a particular discipline, chooses any time and place of study. A student can join an online course from anywhere with Internet access. So, many during the coronavirus epidemic, go to summer cottages or to the village and simultaneously comprehend science in prestigious universities. Disadvantages include high cost of professional platforms and preparation of courses (labor intensive, often expensive), high cost of implementation (purchase of platform, equipment).

Teacher training is a process in which a person acquires and develops new knowledge, skills, abilities and relationships. Therefore, the educational unit should be able to adapt quickly to the conditions of the labor market. Educational training of students should respond flexibly to the current needs of practice. Since education is a continuous process, it is necessary to transfer it to an educational institution, which is a key factor in the formation of the practical competencies of the future professional and the main essence of social partnership with educational institutions. In the context of changes, high requirements are placed on the professional knowledge, skills and skills of a specialist, the level of his personal self-development and creative self-realization in practical activity. The professional standard of the teacher defines a unified approach to professional competencies of specialists and is designed to liberate the teacher, to give a new impetus to its development $[9,10]$.

There are requirements for the elements of personal development of students, because the university forms a modern educational environment that increases mobility, stimulates critical thinking, and forms intelligence. Studies have shown that employers prefer graduates who have a higher level of emotional intelligence [11-13].

The results of a survey conducted by the Superjob research center, during which the degree of prestige of the teacher's profession was revealed and what qualities an ideal 
teacher should have, look like this: $21 \%$ of the citizens surveyed recognize the teacher's profession as prestigious, but only abroad, and not in Russia. Most Russians - 64\% of respondents consider the profession of a teacher to be unattainable. This opinion was most often expressed by people over 45 years old, they accounted for $69 \%$ of people who took part in the survey. In addition, half of Russian citizens - 51\% are convinced that over the past 10 years, the status of a teacher in Russia has decreased, $21 \%$ of respondents believe that the status of a teacher has not changed, and $17 \%$ claim that it has increased. Most participants in the questionnaire believe that the profession of a teacher is very important; its role in teaching and education is great. However, only $6 \%$ of students choose it as their future profession. Most respondents, arguing about the adoption of measures to increase the prestige of the pedagogical profession, are inclined to believe that the main issue can be resolved through wage increases. For $25 \%$, a change in public opinion is important, for $15 \%$ - an increase in motivation.

Problems which are connected with a decrease in the prestige of the profession "teacher" can be solved through increasing the motivation of today's studying general education institutions, which can become interested in this profession and devote themselves to pedagogical activities. To this end, in our opinion, it is necessary to organize focused systematic work, including the following activities: create specialized associations (pedagogical classes), within the framework of which talks, lectures, trainings will be held on the importance of the teacher's profession in the life of modern society, its role in teaching and educating the younger generation;

Hold various kinds of events in schools that reveal the characteristics of the profession of "teacher" for students: days of self-government, workshops, master classes, debates; organize classroom hours in educational institutions, meetings with honored representatives of the profession "teacher";

To post in the media information promoting the prestige of the pedagogical profession (articles about honored teachers of the Russian Federation, about teachers who work within the walls of their native school), to demonstrate thematic advertising videos.

Adapt students to educational institutions using different models of social partnership with employers.

\section{Materials and Methods}

The aim of the present study was to develop an effective model of teacher training based on social partnership with institutions of additional education.

The problem of the shortage of teaching staff in the municipal educational space causes an urgent need to carry out career guidance work from an earlier age. In this regard, in educational practice there was a need for cluster interaction, which would help a holistic and multidimensional learner to know himself, to realize himself in his first important life endeavors, to self-determine and adapt in society. Young students who have made their choices and work with pleasure in the educational sphere are an important strategic resource for the region, society and the state, which make a lot of efforts so that young people can determine their abilities, inclinations, temperament and motivation to become a teacher as early as possible. This is due to the fact that personality formation accounts for a period of adolescent crisis, in which not only fundamental knowledge, sustainable skills and skills are formed, but also needs, a way of thinking, the ability to achieve higher achievements, the desire to teach and teach are laid. That is why the creation of pedagogical and specialized classes of a pedagogical orientation is especially relevant. The methodological basis for the development of a model for the training of teachers was the ideas of T.I. Vlasova about the spiritual and ontological approach in education and education [14], and the ideas of V.V. Abraukhova about the development of the creative 
orientation of the personality [15]. They were the basis for the development of the project "Pedagogical Consortium," based on the principles of social partnership, which actualized the need for cooperation between various collective actors. The consortium included the Department of Theory and Methodology of Vocational Education of DSTU and institutions of additional education: the Center for Additional Education of Children of the Oktyabrsky District of Rostov-on-Don, the Center for the Development of Creativity of Children and Youth of the Pervomaisky District in Rostov-on-Don. The institutions have developed a regulatory framework: an order to create an association of high school students "Pedagogical Class," a Regulation on unification, a program of theoretical and practical training has been developed, project partners and a platform for its implementation have been determined, curators from among teachers of additional education have been identified, a page has been created on the website of institutions and the VKontakte group.

The purpose of the project is to organize career guidance work among adolescents who show interest in the pedagogical profession, the development of competencies necessary for pedagogical activities; conducting pedagogical practice of students of the faculty "Psychology, pedagogy and defectology" on the basis of institutions.

The basis is the cluster principle of unification, which contains a large educational resource for specialized training. The partners of the project were: the Information Center for Atomic Energy of Rosatom Corporation on the basis of DSTU (Don State Technical University) and educational institutions, whose high school students plan to connect their future professional activities with pedagogy and psychology. This principle promotes more extensive and universal specialized education.

It is planned to implement the project within three years. During this time, high school students will have the opportunity to fully enter and master the basics of the pedagogical profession. First of all, it is an opportunity to acquire elements of the necessary basic knowledge in the field of pedagogy and psychology. In practice, familiarize yourself with various forms of conducting lessons and extracurricular activities, classes in institutions of additional education. In addition, students have the opportunity to participate in project activities under the guidance of teachers of the DSTU, teachers and methodologists of additional education centers, experienced teachers of schools in the city. The project gives a start and provides an excellent opportunity for its participants to enter precisely the psychological, pedagogical and pedagogical directions of DSTU - the reference university of our region.

The course program "Pedagogical Consortium" has a modular structure: "Introduction. The history of the formation of pedagogy as a science, "" Fundamentals of pedagogical design, "" Fundamentals of pedagogical communication, "' Pedagogical technologies, "'" Fundamentals of pedagogical excellence. "

The program allows you to get acquainted with the main areas of activity of the teacher, and is focused on the formation of sustainable motivation for the profession.

The method of immersion in the profession is a priority. In addition to theoretical classes, children participate in master classes and open classes. This makes it possible to carry out self-diagnostics of pedagogical abilities.

In this educational project, the main thing is not how much knowledge itself, how much the ability to extract knowledge, transfer it, filter it, integrate it, turn it into a new type of knowledge, and a special role in the implementation of the project is assigned to teachers of additional education. This mission is not accidentally assigned to them, since the basis of the personnel potential of the additional education system is not only professionally trained teachers, but also specialists in various fields and types of art, sports, applied and technical creativity. The peculiarity of the profession of "teacher of additional education" consists in the unity of two components: pedagogical and specialized, each of which carries a creative component. Classes are conducted by professional and creative craftsmen who love their 
profession, possess modern educational technologies, are creative in solving tasks, are engaged in constant professional self-development, and have a high level of recognition by the pedagogical community, students and their parents. They willingly share professional secrets, strive to reveal the features of the teacher's profession as much as possible, so that in the future it will become a vocation for children.

At the introductory lesson, the participants were presented with presentation material with the characteristics of 29 pedagogical professions, according to the results of which a questionnaire of professional pedagogical preferences was conducted.

The children selected the following areas of pedagogical activity: kindergarten teacher (preschool teacher), defectologist, juvenile inspector, correctional teacher, speech therapist, master of professional training, neuropsychologist (clinical psychologist), teacher of additional education, English teacher, psychologist, sign language teacher, primary school teacher, school teacher.

This information led to the identification of a direction and the development of a training and thematic plan for the sessions.

Students were given an alternative to the traditional form of education, which is possible only in the system of additional education. During the school year, every week the pedagogical class gathered its students - schoolchildren from six districts of the city Voroshilovsky, Kirovsky, Leninsky, Pervomaisky, Oktyabrsky, Sovietsky.

According to the conceptual approaches used during the implementation of the project, the expert who reflexively determines the boundaries of his capabilities and understands what the situation requires of him, which means that by the middle of the course they decided on the choice of further participation in the project of 18 high school students from four districts of the city - Voroshilovsky, Pervomaisky, Oktyabrsky, Sovetsky.

Teachers-psychologists conducted training for the cohesion of the group; starting diagnostics (creative and communicative qualities, readiness for self-development); interactive lesson "Tolerance as a component of pedagogical culture and pedagogical competence"; methods of psychological diagnostics in the work of a teacher; occupation "Conflict, secrets of conflict-free behavior"; Training in conflict management skills; Training in public speaking skills.

Theoretical knowledge on the basics of pedagogy (analysis and introspection of the lesson, the structure of the lesson, didactic aspects, the main categories and problems of pedagogical communication, the essence of the learning process in a modern school, preparation of the teacher for the lesson) was taught by undergraduates of DSTU. Experienced school teachers and teachers of additional education prepared master classes "Conducting an experiment lesson," "Fundamentals of extra-time activities of future teachers," "Opportunities for using information technologies in the lesson." The presented mobile class model made it possible to get acquainted with the capabilities of the digital USB microscope MIKMED 2.0, how to connect it, the peculiarities of the software and the rules of work on German. Students were able to use a digital microscope when performing individual research work, Following a discussion of the results of the study, which showed that a lesson using ICT is informative, interactively, saves time, allows each student to work at their own pace, and the teacher to pay attention to each student, quickly monitor and evaluate the results of training.

O.G. Sevryukova, head of the robotics laboratory, introduced future teachers to the use of innovative technologies in the educational process. In real time, with the help of modern technology, the guys could go to the network sites of the educational community. Get acquainted with the structure and content of educational social networks, the largest educational platforms. They got the opportunity to discuss the system of mobile training, the mass open online course (MOOC), virtual training, the advent of the so-called era of electronic pedagogy. 
The organization of leisure events in working with children and the holding of the family theatrical holiday "Eh, Maslenitsa!" High school students mastered in a practical lesson, which was prepared and conducted by Blinkova S.E., an organizer teacher.

Within the framework of the topic "Fundamentals of pedagogical design," the children were offered thirty-nine topics of pedagogical research projects, the implementation and protection of which became an indicator of the successful development of a professionally oriented program. Each young teacher is defined as a mentor.

During the primary diagnosis, the communicative and organizational abilities of students and their self-esteem of personality were surveyed.

Diagnosis was carried out according to the following methods. To assess communicative and organizational abilities, the methodology "Communicative and organizational inclinations" was used (V.V. Sinyavsky, V.A. Fedoroshin (KOS)), it was proposed to answer "yes" or "no" to the list of questions. Then raw scores were calculated the number of answers matching the key for each section of the methodology, after which the estimated coefficients were calculated separately for communicative and organizational abilities according to the formula. The estimated coefficients range from 0 to 1 . Indicators close to 1 indicate a high level of communicative and organizational abilities, close to 0 - a low level.

Based on the results of the diagnosis, the following results were obtained. The indicators of communicative abilities revealed very high, high, medium, below average and low levels of severity of this indicator:

A very high level was found in $33.3 \%$ of students. They have a need for communicativity and actively strive for it, casually behave in a new team, prefer to make independent decisions in an important business or in a difficult situation, defend their opinion and ensure that it is adopted by comrades, persist in the activities that attract them. They themselves are looking for things that would satisfy their need for communication.

A high level was found in $11.1 \%$ of students. They are not lost in the new environment, quickly find friends, constantly strive to expand the circle of their acquaintances, help relatives, friends, take the initiative in communication, are able to make an independent decision in a difficult situation. They do all this not under duress, but according to internal aspirations.

The average level was identified in $16.7 \%$ of students. They strive for contacts with people, do not limit the circle of their acquaintances, defend their opinion, plan their work, but the potential of their inclinations is not distinguished by high stability. Communicative tendencies need to be developed and improved.

The level below average was identified in $27.8 \%$ of students. They do not seek communication, they feel constrained in a new company, team; prefer to spend time alone with themselves, limit their acquaintances; have difficulties in reaching out to people; do not navigate well in an unfamiliar situation; do not defend their opinions, are hard to endure resentments.

A low level was found in $11.1 \%$ of students. Such children are characterized by a low level of manifestation of communicative tendencies.

As can be seen from the data obtained, the largest percentage of children are children with a very high level of communication skills. A large percentage of children with belowaverage levels of communicative ability were also identified. Thus, we can argue that most students have a very high level of communication skills.

The indicators of organizational abilities also revealed very high, high, medium, below average and low levels of severity of this indicator:

A very high level was found in $27.8 \%$ of students. They have a need for organizational activity and strive for it, quickly navigate in difficult situations, are proactive, prefer to make independent decisions in an important business or in a difficult situation, can 
reinvigorate unfamiliar company, like to organize different games, events, they themselves are looking for such things that would satisfy their need for organizational activity.

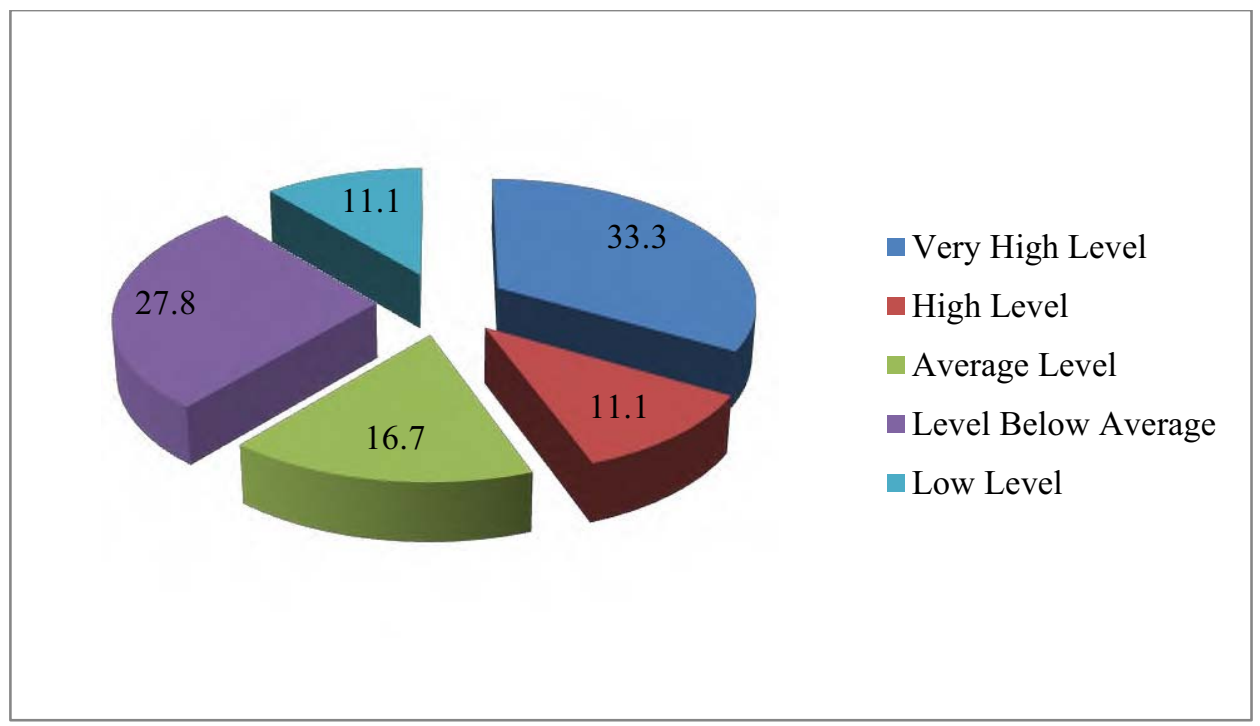

Fig.1. The Level of communicative tendencies

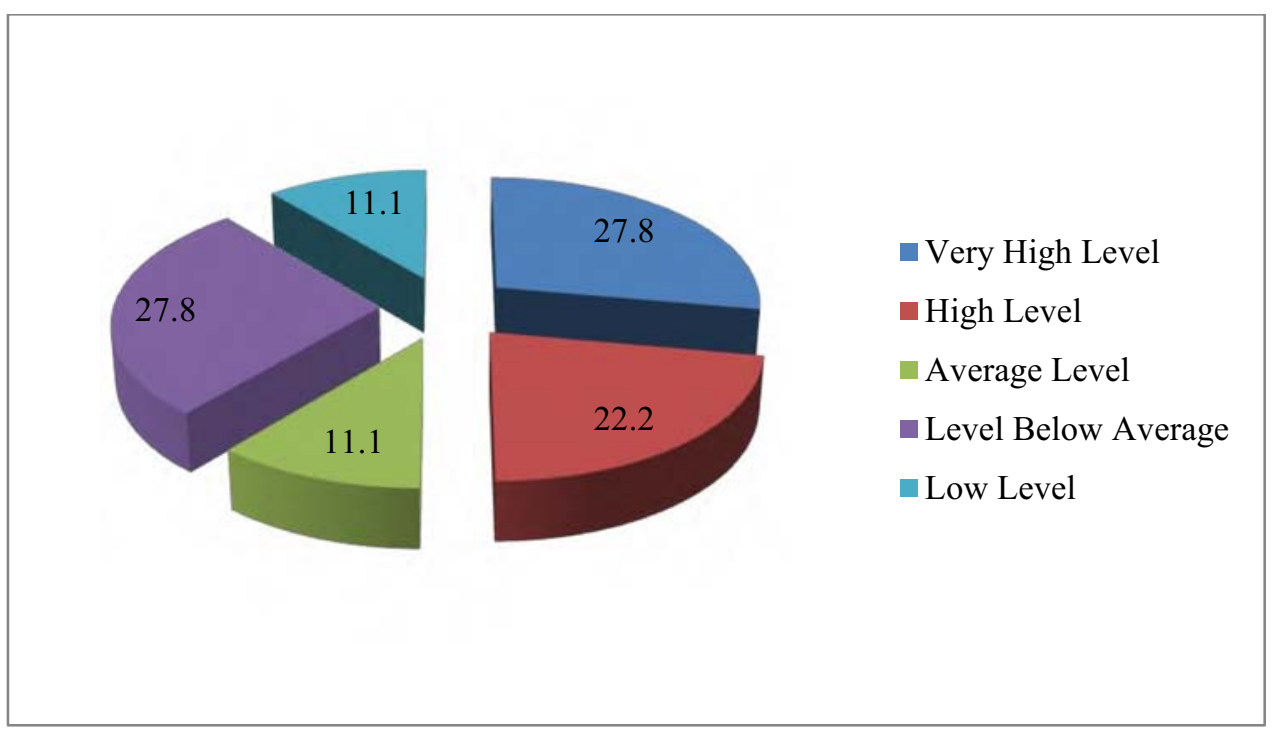

Fig.2. The Level of organizational tendencies

A high level was found in $22.2 \%$ of students. They are not lost in the new environment, engage in social activities, help relatives, friends, take part with pleasure in organizing public events, are able to make an independent decision in a difficult situation. They do all this not under duress, but according to internal aspirations.

The average level was identified in $11.1 \%$ of students. They defend their opinion, plan their work, but the potential of their inclinations is not distinguished by high stability. Organizational tendencies need to be developed and improved.

The level below average was identified in $27.8 \%$ of students. They do not seek communication, prefer to spend time alone with themselves, have difficulties speaking to 
the audience; do not navigate well in an unfamiliar situation; do not defend their opinions, the manifestations of initiative in public activities are extremely reduced, in many cases they prefer to avoid making independent decisions.

A low level was found in $11.1 \%$ of students. Such children are characterized by a low level of manifestation of organizational tendencies.

As can be seen from the data obtained, the largest percentage of children is also children with a very high level of organizational skills. In addition, a large percentage of children with a level of severity of organizational abilities is below average, and a fairly high percentage of high level of organizational abilities is observed. In accordance with this, we can also argue that most students have a very high level of organizational skills.

It should also be noted that most children who received medium, high and very high results in terms of communicative abilities also received medium, high and very high scores in terms of organizational abilities.

Thus, according to the data obtained during the diagnosis, it can be concluded that about $50 \%$ of the children of the presented content have high and very high rates of communicative and organizational inclinations. Children are not lost in the new environment and have a need for sociability and organizational activity, quickly find friends and navigate a new team and difficult situations, are proactive, defend their opinion, help relatives and friends, are able to make an independent decision in a difficult situation, can reinvigorate an unfamiliar company, like to organize various games, events, perseverance in activities that attract them. They do all this not under duress, but according to internal aspirations.

The experience of implementing this project in the system of additional education has shown the effectiveness of interaction of all its participants. Its further development will allow the children to make a conscious choice and decide on the future profession as soon as possible, which may at least partially solve the problem of the shortage of pedagogical personnel in our city.

\section{Results}

The result of this study was the development of an effective model for the formation and development of the personality of the future teacher. Model includes secondary to higher education levels

The unity of goals implemented by the university and social partners is combined with the variability of education, the variety of types of educational institutions, forms and technologies of education.

The purpose of the project is to organize career guidance work among adolescents who show interest in the pedagogical profession, the development of competencies necessary for pedagogical activities; conducting pedagogical practice of students of the faculty "Psychology, pedagogy and defectology" on the basis of institutions.

The basis is the cluster principle of unification, which contains a large educational resource for specialized training. Partners of the project were: Information Center on Atomic Energy of Rosatom Corporation on the basis of DSTU and institutions of additional education of the city of Rostov-on-Don

\section{Discussion}

Today, the practical orientation of pedagogical education becomes obvious. At the same time, the introduction of digital information technologies into the educational process becomes obvious. Innovations in the model of pedagogical education should combine 
traditions and innovations, strive for harmony in the formation of a cognitive and spiritualmoral beginning in a person. It remains relevant to solve the problems of educating the younger generation on the basis of the values of good, citizenship and patriotism, and at the same time adapt to new socio-economic conditions, where creative independence, business communication, and high professional training will be in demand.

\section{Conclusions}

DSTU (Don State Technical University) today is the largest scientific and educational center in the South of Russia. The university received the status of a reference, as it is focused on satisfying the region's request for the training of highly qualified personnel, where the first tasks are the development of research infrastructure, focusing on a qualitatively new level of training of practitioners whose knowledge and competence meet modern educational needs.

The university has a diverse level structure of educational organizations and units for building continuous models of specialized education.

DSTU (Don State Technical University) today is the largest scientific and educational center of the South of Russia, where the priority tasks are the development of the research infrastructure, focusing on a qualitatively new level of training for practitioners whose knowledge and competencies meet the current needs of the largest enterprises in the region The conclusion is that higher education is characterized by high sensitivity on both sides. $[14,15]$.

The university unites educational organizations of different levels under its foundation. The structure of the university includes kindergartens, a gymnasium, a lyceum, colleges, a department of further education, a Children's University, etc. The university has a resource base for building continuous models of specialized education.

\section{References}

1. E. Davoine, C. Ravazi, European Management Journal, 31(2), 152-163 (2013)

2. S. Minocha, D. Christov, S. Leahy-Harland, The International Journal of Management Education, Volume 16, Issue 02.2018, 245-255, Social Science Research, 74, 45-61 (2018)

3. L. G. Hammershøj, Futures, The perfect storm scenario for the university: Diagnosing converging tendencies in higher education, 111, 159-167 (2019) doi.org/10.1016/j.futures.2018.06.001

4. S. Hasanefendic, M. Heitor, H. Horta, Technological Forecasting and Social Change, Training students for new jobs: The role of technical and vocational higher education and implications for science policy in Portugal, 113(B), 328-334 (2016) doi.org/10.1016/j.techfore.2015.12.005

5. J. A. Martin, K. A. Heppar, S. G. Green, Business Horizons, Taking international business education programs and pedagogy to new heights: Fundamental questions for educators and students, 54(4), 355-363 (2011) doi.org/10.1016/j.bushor.2011.03.002

6. M. Romero, Procedia - Social and Behavioral Sciences, 174, 115-121 (2015)

7. A. L. Mainecke, K. K. Smith, N. Lehmann, Willenbroke, 44(4), 428-445 (2013) doi:10.1177/1046496413487020

8. S. Waibela, K. Petzold, H. Rüger, Social Science Research, 74, 45-61 (2018) doi: 10.1016/j.ssresearch.2018.05.006 
9. A. Voisina, X. Dumay, Teaching and Teacher Education, How do educational systems regulate the teaching profession and teachers' work? A typological approach to institutional foundations and models of regulation, 96, 103144 (2020) doi.org/10.1016/j.tate.2020.103144

10. J. Novakovich, S. Shaw, S. Miah, Computers \& Education, Designing curriculum to shape professional social media skills and identity in virtual communities of practice, 104, 65-90 (2017), doi.org/10.1016/j.compedu.2016.11.002

11. Z. Chodasová, Z. Tekulová, L. Hl’ušková, S. Jamrichová, Procedia - Social and Behavioral Sciences, 174, 3170-317 (2015)

12. M. Anghela, Procedia - Social and Behavioral Sciences, 142(14), 19-23 (2014) doi: 10.1016/j.sbspro.2014.07.580

13. A. Jameson, A. Karthia, C. McGuinness, F. MacSwinib, Procedia - Social and Behavioral Sciences, 228, 515-522 (2016) doi:10.1016/j.sbspro.2016.07.079

14. A. Corelli, Procedia - Social and Behavioral Sciences, Direct vs. Anonymous Feedback: Teacher Behavior in Higher Education, with Focus on Technology Advances, 195, 52-61 (2015)

15. J. E. Relf-Eckstein, A. T. Ballantyne, P. W. B. Phillips, NJAS - Wageningen Journal of Life Sciences, Farming Reimagined: A case study of autonomous farm equipment and creating an innovation opportunity space for broadacre smart farming, 90-91, 100307 (2019) doi.org/10.1016/j.njas.2019.100307 